\title{
Dental care for children and young people who have a hearing impairment
}

\author{
J. Champion, ' and R. Holt, ${ }^{2}$
}

Aim The aim was to determine whether there are indications that hearing-impaired children experience difficulties in accessing dental care and/or in receiving dental treatment.

Method The study was carried out by means of a questionnaire. Parents of 84 children contacted through the National Deaf Children's Society returned completed questionnaires.

Results Eighty-two children (98\%) had visited a dentist. Nearly two-thirds $(63 \%)$ were reported to have at least one problem in communication while receiving dental care, this increased significantly as the severity of the hearing impairment increased. Fifty-nine children $(70 \%)$ reported having at least one problem in communication at the doctors. Fifty-two (62\%) reported that the dentist had worn a mask while communicating with the child and $48(57 \%)$ that there had been background noise in the surgery during appointments.

Conclusions Removing masks while talking, reducing background noise and learning to use simple signs may improve communication with hearing-impaired children.

There are between 23,000 and 25,000 children (aged $0-15$ years)
who are permanently deaf or hard of hearing in the UK. Many
more experience temporary hearing problems in early childhood.
Of those with permanent deafness, about 16,000 were born deaf or
became deaf in the first few years of life. About 8,000 children were
severely or profoundly hearing-impaired.
A hearing impairment primarily influences communication, on
which it can have a devastating effect. As the degree of loss
increases, psychological, emotional and social disturbances gener-
ally become more pronounced. ${ }^{2}$ The extent of disturbance also
depends on age of onset, training, and acceptance of disability.
Many methods of communication have become available to
enable the hearing-impaired to function in a normal way and not
to be disabled by their hearing loss. Many of those with a hearing
impairment rely wholly or partly on lip reading. Other methods
include British Sign Language (BSL), Finger Spelling, Signed
English, Signed Supported English (SSE) and Cued Speech. BSL
is a manual/visual means of communication that incorporates
both national signs and regional variations. The signs of BSL are
frequently used in conjunction with finger-spelled words based

${ }^{1}$ Research Fellow, ${ }^{2}$ Senior Lecturer, WHO Collaborating Centre for Disability, Culture and Oral Health, National Centre for Transcultural Oral Health, Eastman Dental Institute, 256 Gray's Inn Road, London WC1X 8LD, UK. Correspondence to: Dr Ruth Holt, WHO Collaborating Centre for disability, culture and oral health, National Centre for Transcultural Oral Health, Eastman Dental Institute, 256 Gray's Inn Road, London WC1X 8LD

email:R.Holt@eastman.ucl.ac.uk

REFEREED PAPER

Received 20.12.99; accepted 09.03.00

() British Dental Journal 2000; 189: 155-159 on 26 different hand positions representing the 26 letters of the alphabet. Signed English represents the English language grammatically and also incorporates Finger Spelling. SSE uses signs for key words to support oral communication. Finally, Cued Speech uses different hand shapes close to the speaker's mouth to help to differentiate sounds normally invisible with lip reading.

There are many aids to communication for those with some hearing, such as hearing aids, induction loops and infrared systems and, for telephone communication, Text-phones, and Typetalk systems. The Typetalk service might be particularly useful for dental staff to be familiar with as it allows deaf people to make calls to hearing people without any need for a Text phone. The service is operated by the Royal National Institute for Deaf People and funded by BT. A Typetalk operator, who is bound by a strict code of confidentiality, will take a typed message from a deaf person using a Text phone and relay it by voice to a hearing person. The operator then types replies back to the deaf person.

A variety of suggestions have been put forward as to the management of hearing-impaired patients including simple measures such as not calling the patient from the waiting room using solely verbal means, and, for children, using posters, brochures and pictures to help explain procedures and asking the parent to remain in the child's view. ${ }^{3}$ Because they are unable to communicate verbally, a deaf child may express themselves by other means. ${ }^{3}$ Dentists need to be sensitive to non-verbal communication such as facial expressions, postures and movements as a means of conveying feelings. ${ }^{4}$ Affected children may have a poor tolerance for delays; these should be avoided and procedures kept short. ${ }^{2}$

Those with hearing impairments are reported to experience significant problems in accessing health care and in communicating with doctors. Lack of sign language and of awareness training among health service staff and the shortage or absence of aids to communication have also been pointed out. These include fax and minicom systems as well as interpreters and advocates. Reported dental attendance appears to be good but the majority of studies have focused on general health services and have been confined to adults. There has been little consideration of dental care or of care for children with hearing impairments. Studies have mostly been carried out through charitable organisations concerned with helping individuals with a hearing impairment, perhaps because of the difficulty in obtaining sufficient sample sizes through more conventional methods.

The National Deaf Children's Society (NDCS) is the leading national charity concerned with the needs of children and young people with hearing impairments. The society offers assistance and advice regarding health and social services as well as education and welfare rights. Financed through voluntary contributions, NDCS works throughout the United Kingdom by means of 
regional and local representatives. Representatives support, represent and advise individual families with hearing-impaired children and young people.

The aim of the present study was therefore to determine whether there are indications that children with hearing impairments experience difficulties in accessing dental care or during attendance at the dentist.

\section{Methods}

The study was carried out in partnership with the NDCS by means of a questionnaire distributed through the regional and local representatives.

The questionnaire was designed jointly by the authors and NDCS. Most questions were closed but open questions were used to elicit examples of good practice.

In the first section, questions included details of the child's name, date of birth and postcode, and occupation of the mother and partner (if appropriate). The second included questions on severity of the hearing impairment, method of communication used and the type of school that the child attended. Questions used in the third section related to past dental attendance and treatment. Where possible these were drawn from the questionnaire used in the most recent national survey of child dental health. ${ }^{5}$ The fourth section was concerned with commonly perceived problems in accessing dental care. To put this into context, questions about perceived problems with medical care were also included. Parents were asked specifically about difficulties with getting an appointment for their child, or during attendance. Families were then asked to indicate examples of positive experiences they had encountered or ways in which they thought procedures could be improved at the dentist.

The nature and purpose of the study was explained at a meeting of Regional Representatives held in December 1998. Copies of the proposed questionnaire, accompanying information sheet and consent form were circulated at the meeting and comments invited. Suggested modifications were agreed and incorporated after the meeting. Three local representatives completed and returned copies of the questionnaire for their own children to allow a final check.

Representatives were asked to circulate the questionnaire together with a covering letter and information sheet to families with whom they had contact and to collect and return completed forms. Representatives included those families who they thought would be willing and able to take part in the study.

To encourage response, all representatives received at least two reminders. The Society newsletter also included an item of publicity about the survey to encourage response.

Data from completed questionnaires was entered into an SPSS spreadsheet and analysed using chi-squared tests to compare frequencies between those with a profound hearing impairment and those with severe, moderate or mild hearing loss.

\section{Results}

Completed questionnaires were returned from families of 84 children. Thirty-four (41\%) of the children were girls, 48 (57\%) boys and for $2(2 \%)$ gender was not indicated. Fifty-five $(66 \%)$ replies came from England, 15 (18\%) from Wales, 7 (8\%) from Northern Ireland and $6(7 \%)$ were from Scotland. For one child the postcode was not known.

Thirteen of the children who took part were under 5-years-old, 33 between 5 and 9 years, 30 were 10 to 15 years and 6 were over 16 . Age was not indicated for two children.

Fifty-two of the 84 children (62\%) had a profound hearing loss and $20(24 \%)$ had one that was severe. Ten were reported to have a moderate impairment and one child a mild loss (severity was not reported for one). For 59 the impairment had been present from birth, and for a further 13 it had developed before 1 year of age. For 10 children, their hearing loss had developed between 1 and 5 years and for one child it had developed when they were older than this (the age at which impairment had developed was not indicated for one child). Sixty-two of the children attended either a special school or a school with a special unit ( 45 of whom had a profound hearing impairment) and 17 a mainstream school ( 4 of whom had a profound impairment). School type was not indicated for 5 children (including 3 with a profound loss).

Using the Registrar General's Classification of Occupations, 35 children came from families in Classes I-IIINM and 31 from families classified as IIIM-V. Eighteen children could not be classified in this way.

The number using different communication skills is shown in Figure 1. Methods included oral communication (45 subjects), lip-reading (34), British Sign Language (BSL)(33), Sign Supported English (SSE)(23) and Cued Speech (3). Other methods (9 children) included Makaton (where only key words in a sentence are signed, the rest is spoken) and Total Communication (where all forms of communication such as speech, formalised gestures, finger spelling, lip-reading and writing are used).

Fifty-one children used more than one skill. Fifty-eight children could use either oral communication or lip reading or both but 25 were wholly dependent on other means.

\section{Oral healthcare}

Eighty-two of the 84 children were reported to have attended a dentist. Seventy were reported to have made their first visit to a dentist before the age of 5 years and 14 later than this. Thirty-five of the children with a profound hearing loss were reported to have started attending a dentist before 4 years $(67 \%)$ compared with 28 (90\%) of those with a less severe impairment $(P<0.05,95 \% \mathrm{CI}$ for the difference in percentage $=21-25 \%$ ).

Forty-five of the children were reported to have received some form of treatment and 38 had received none (for one child it was not indicated). The types of treatment received are listed in Figure 2. Twenty-five children had at least one tooth extracted (in 19 cases under general anaesthesia) and 24 had restorative care. Eighteen children had one or more items of preventive care.

Children with a profound loss of hearing were more likely never to have had a filling or extraction $(P<0.05,95 \% \mathrm{CI}$ for the difference in percentage $=12-17 \%)$. Fourteen of 52 children with a profound

Table I Communication difficulties at the dentist 42 children had $>$ I difficulty therefore numbers exceed 53

\begin{tabular}{|c|c|c|c|}
\hline Type of difficulty & $\begin{array}{l}\text { No. of children } \\
\% \text { of all children }) \\
\quad(n=53)\end{array}$ & $\begin{array}{l}\text { No. of children I } \\
\text { with profound } \\
\text { hearing loss }\end{array}$ & $\begin{array}{l}\text { No. of children with } \\
\text { mild - severe } \\
\text { hearing loss }\end{array}$ \\
\hline At least I difficulty ${ }^{\dagger}$ & $53^{*}(63.1)$ & 37 & 15 \\
\hline $\begin{array}{l}\text { Being called from } \\
\text { the waiting room }\end{array}$ & $32 *(38.1)$ & 22 & 9 \\
\hline $\begin{array}{l}\text { Communicating with } \\
\text { the dental nurse }\end{array}$ & $35 *(4 I .7)$ & 26 & 8 \\
\hline $\begin{array}{l}\text { Communicating with } \\
\text { the dentist }^{\ddagger}\end{array}$ & $44 *(52.4)$ & 30 & 13 \\
\hline $\begin{array}{l}\text { Understanding what } \\
\text { will take place at the visit }\end{array}$ & it $39 \quad(46.4)$ & 26 & $13^{*}$ \\
\hline
\end{tabular}

*Degree of loss unknown for one subject

${ }^{\dagger}$ Chi-squared $=4.9, \mathrm{df}=\mathrm{I}, \mathrm{P}<0.05$

${ }^{\ddagger}$ Chi-squared $=5, \mathrm{df}=\mathrm{I}, P<0.05$ 
Table 2 Communication difficulties at the doctors'

49 children had $>$ I difficulty therefore numbers exceed 59

\begin{tabular}{ccc}
\hline Type of difficulty & $\begin{array}{c}\text { No. of children } \\
(\% \text { of all children })\end{array}$ \\
$(n=59)$ & profound hearing & $\begin{array}{c}\text { No. of children with } \\
\text { mild - severe } \\
\text { hearing loss }\end{array}$
\end{tabular}

\begin{tabular}{|c|c|c|c|c|}
\hline At least I difficulty & 59 & $(70.2)$ & 40 & 19 \\
\hline $\begin{array}{l}\text { Being called from } \\
\text { the waiting room }\end{array}$ & 41 & (49) & 29 & 12 \\
\hline $\begin{array}{l}\text { Communicating with } \\
\text { the nurse }{ }^{\dagger}\end{array}$ & 40 & $(47.6)$ & 30 & 10 \\
\hline $\begin{array}{l}\text { Communicating with } \\
\text { the doctor }\end{array}$ & $51 *$ & $(60.7)$ & 34 & 16 \\
\hline $\begin{array}{l}\text { Understanding what } \\
\text { will take place at } \\
\text { the visit }\end{array}$ & $40 *$ & (48) & 28 & 11 \\
\hline
\end{tabular}

*Degree of loss unknown for one subject

${ }^{\dagger}$ Chi-squared $=6.9, \mathrm{df}=\mathrm{I}, P<0.01$

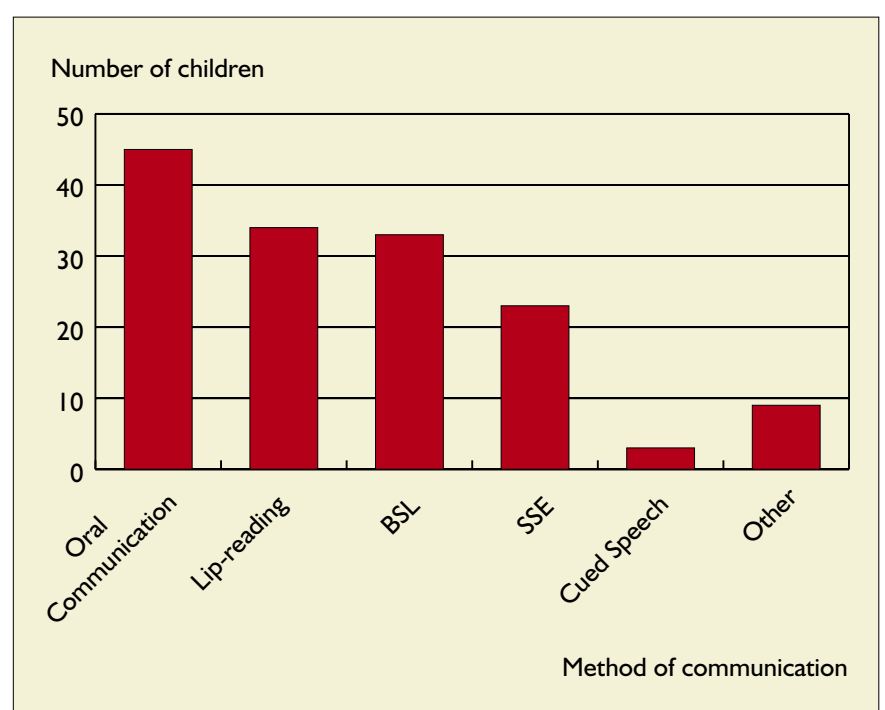

Fig. I Methods of communication used by children with hearing impairments $(n=84)$ ( $n$ b 5 I children used $>$ I type of communication therefore numbers exceed 84)

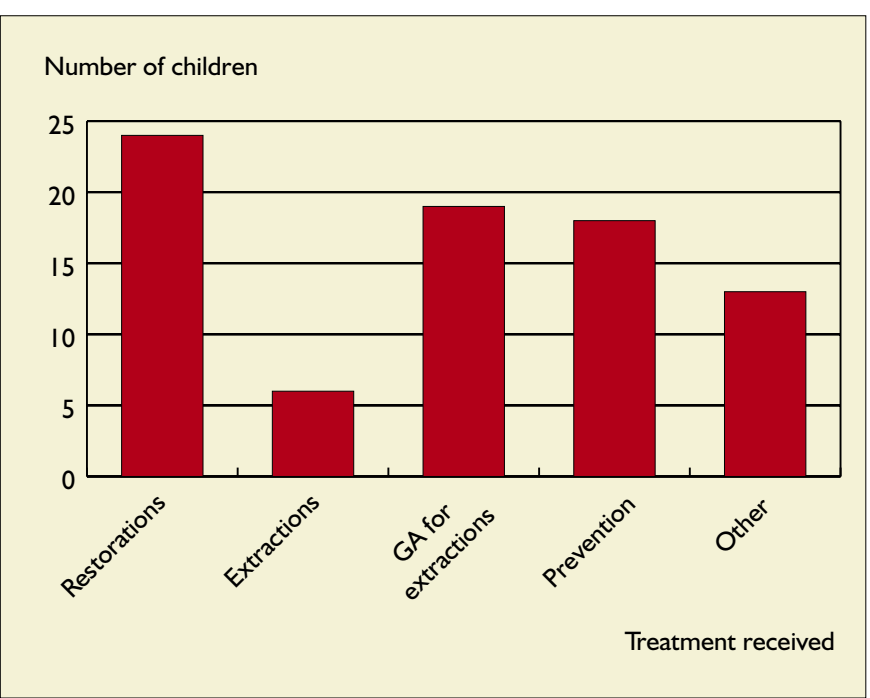

Fig. 2 Types of treatment received by children with hearing impairments $(n=45)(\mathrm{nb} 29$ received $>$ I type of treatment therefore numbers exceed 45) impairment had received restorations, and 13 had had an extraction compared with 10 of 31 less severely affected children who had restorations and 10 who had teeth extracted.

Ten families reported difficulties in getting an appointment: for five children this was because the dentist was so busy; for two because of the difficulties in communication; one because of the child's anxiety; one because the dentist only treated private patients; and one seeking orthodontic treatment had difficulties because of their age (16 years).

Problems experienced at the dentist

Numbers of children having different types of communication difficulty at the dentist are shown in Table 1 . These are also shown in Figure 3 (together with the numbers having difficulty during visits to the doctors'). Fifty-three children were reported to have had at least one of the difficulties, communicating with the dentist being the most common.

Difficulties were more commonly reported for children who were profoundly deaf than those less severely impaired.

Parents of 27 children said that the dentist always wore a mask when communicating with them and a further 25 said that they sometimes did so. In the case of 30 children there was always background noise in the surgery, such as music or traffic, for a further 18 children there was sometimes background noise.

\section{Problems experienced at the doctors'}

Numbers of children having different types of communication difficulty at the doctors' are shown in Table 2 (and in Figure 3). Fifty-nine children were reported to have had at least one of the difficulties, communicating with the doctor being the most common.

\section{Qualitative findings}

Twenty-nine respondents gave examples of good practice that either they had experienced or would like to have seen when visiting the dentist. These findings are shown in Table 3.

\section{Discussion}

The aim of this study was to look for indications that children with hearing impairments experience difficulties in access to dental care or when they visited a dentist. The sample size was small and the method of selection such that the group could not be regarded as necessarily being representative. The high proportion of children included who had a profound hearing impairment shows that bias was present $(62 \%$ compared with an estimated $24 \%$ among children in the UK with a significant impairment $)^{6}$. Reaching large unbiased samples of this special group by conventional sampling methods is likely to be both difficult and expensive. Despite its weaknesses the study sample included children from all over the UK and from a wide range of age, social class background and severity of impairment. At a minimum, findings might therefore be of value in justifying the resources needed for further, more robust studies.

Overall, parents reported little difficulty in access to care. The great majority of children (98\%) were reported to have visited a dentist, findings similar to results in the National Survey of Child Dental Health ${ }^{5}$ and suggesting that accessing dental care may not have been perceived as a problem by parents of this particular group of children. Adults with hearing impairments have also reported a high level of dental attendance. ${ }^{7,8}$

Only in relation to the age at first dental visit did the impairment appear to have had any effect on attendance. Children who had a profound hearing impairment were $23 \%$ less likely to have visited a dentist before the age of 5 years than were those with a less severe hearing loss. This result may represent a chance finding or may reflect difficulties in dental attendance in younger children with profound hearing loss. Efforts by schools and special units and by 
Fig. 3 Communication difficulties experienced by children with hearing impairments (nb 42 children had > I difficulty at the dentist therefore numbers exceed 53 and 49 children had > I difficulty at the doctors' therefore numbers exceed 59)

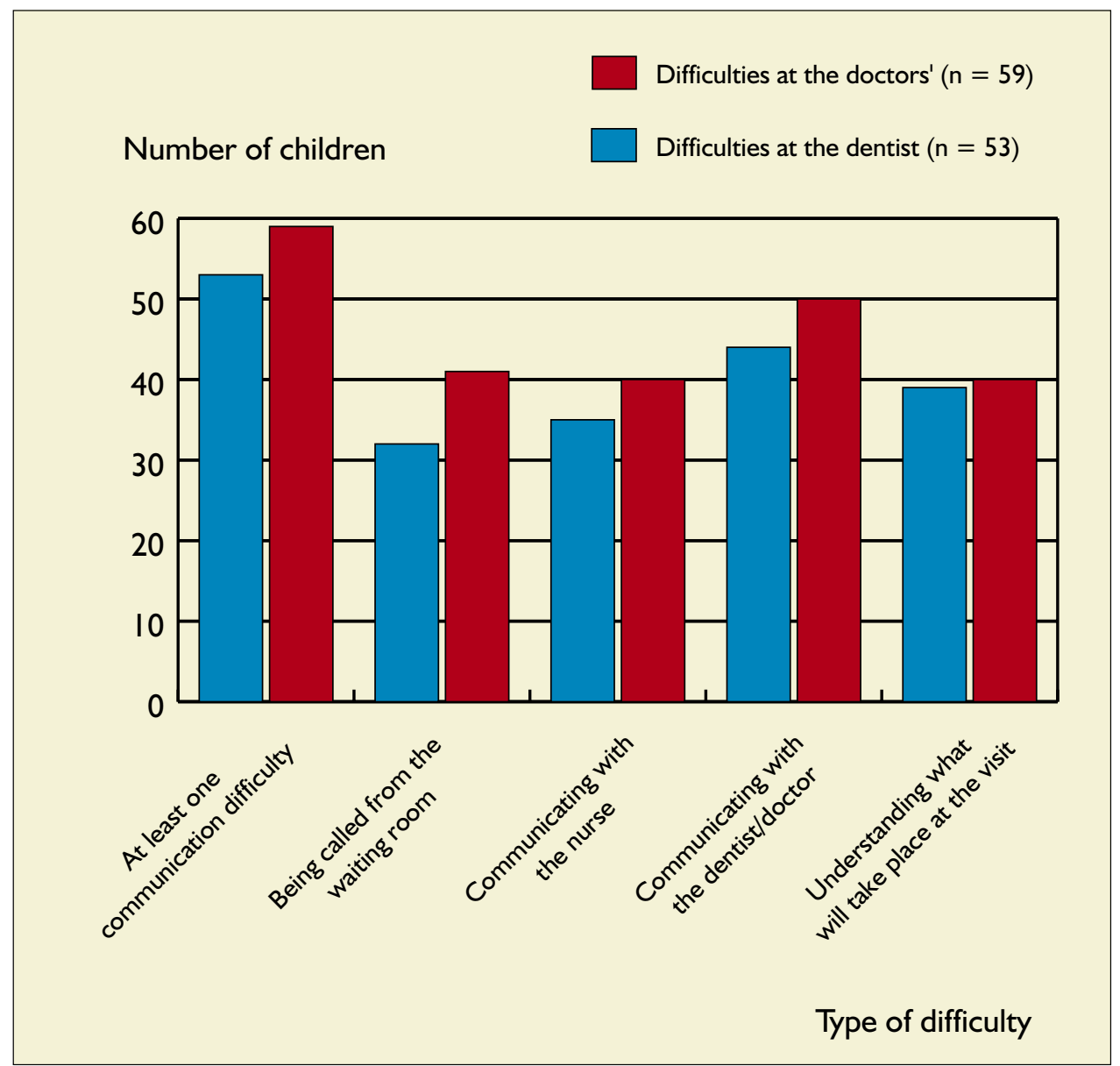

the dental services may help in overcoming this disadvantage once a child starts full time education.

As well as reported attendance treatment received also appeared to be broadly similar to that seen nationally. Children in the present sample may however have been more likely to have extractions. Approximately equal numbers had extractions as had restorations whereas at least $20 \%$ more children in the national survey had restorations. The nature of the sample again makes interpretation difficult but this difference may reflect difficulties in gaining sufficient co-operation for restorative procedures from children who have special difficulties in communication.

Problems experienced while receiving dental care appeared to be common. Nearly two thirds of children were reported to have difficulties in communicating with the dentist/nurse, being called from the waiting room or understanding what will take place during the appointment. Problems were common across the sample as a whole but problems at all, and in communicating with the dental nurse in particular, were reported more often for children who were profoundly hearing-impaired than for those who were less severely affected. That these difficulties are not isolated is shown by the fact that over two-thirds of children were reported to experience similar difficulties at doctors' surgeries. As at the dentists', the likelihood of experiencing problems communicating with the nurse at the doctors' surgery was increased among those with a profound hearing loss.

Parents were asked about their child's methods of communication. More than two-thirds (69\%) of the children were able to use oral communication or lip-reading. These children need quiet surroundings and a clear view of the speaker's face to maximise their understanding but nearly two-thirds of respondents reported that the dentist had worn a mask while communicating with their child and over half reported that there had been background noise such as music or traffic during the appointment. Wearing a mask may be
Table 3 Major issues raised by respondents along with examples of what some respondents actually said

- Deaf awareness (4 respondents ${ }^{\mathrm{a}}$ )

'Greater awareness of the needs of deaf people to communicate directly with the patient by dental/medical people in general.'

- Interpreters (4 respondents ${ }^{\mathrm{a}}, 2$ respondents ${ }^{\mathrm{b}}$ )

'Up till now we (parents) have supported communication in dental (medical) situations. Reaching age where this is an intrusion in our son's right to privacy.'

- Calling systems (4 respondents ${ }^{\mathrm{a}}, 2$ respondents ${ }^{\mathrm{b}}$ )

'The dentist comes out to get (child's name) from the waiting room which is helpful.'

- Sign language (4 respondents ${ }^{\mathrm{a}}, 2$ respondents $\left.{ }^{\mathrm{b}}\right)$

'I would like to see people... maybe learn stage I BSL so they can make deaf person feel at ease.'

- Use of explanatory videos/books (2 respondents ${ }^{\mathrm{a}}$, I respondents ${ }^{\mathrm{b}}$ )

'Subtitled video showing any treatments needed to be done so that the child is fully aware of what is going on.'

- Masks (2 respondents ${ }^{\mathrm{a}}, 3$ respondents ${ }^{\mathrm{b}}$ )

'Dentist pulls mask down to speak to (child's name).'

- Minicom (I respondent ${ }^{\mathrm{a}}$ )

'They should have a minicom.'

- Facing child to communicate (I respondent $\mathrm{t}^{\mathrm{a}}$ )

'Dentist shouldn't talk to them whilst patient laying down and dentist is behind patient and upside down.'

- Educational advice (I respondent ${ }^{\mathrm{a}}$ )

'Help with tooth brushing for deaf ...some kind of I-I teaching.'

- Positive attitude ( 3 respondents ${ }^{b}$ )

'He was brilliant, very patient indeed... he's relaxed, I'm relaxed, they're relaxed.'

Respondents ${ }^{\mathrm{a}}=$ number of respondents who would like this issue addressed Respondents $^{\mathrm{b}}=$ number of respondents who have seen this issue addressed 
justified as a measure to control cross infection, but pulling the mask down from over the lips during speech, allowing a child to lip-read, would help to improve understanding. Reducing noise by turning off background music or closing windows is another simple means to help.

Dentists should routinely enquire about a child's preferred means of communication. For many children, simple measures such as removing masks and reducing noise may be sufficient but in the present study nearly a third (30\%) of the children needed special communication techniques such as sign language or cued speech for communication. It has been suggested that all dentists should learn simple sign language and principles of communication with those who have hearing impairments. ${ }^{9}$ Dentists of 3 of the 84 children were reported to be especially trained to treat children with hearing impairments and those of 3 others were able to use cued speech or sign language.

Comments and suggestions made by parents that may help children with hearing impairments included the broad recommendations that staff should be more aware of deaf issues as well as being able to use some basic sign language. Parents suggested that interpreting support should also be made more accessible as should appropriate equipment such as minicoms (text telephones) and deaf friendly call systems in waiting areas. These suggestions are very similar to recommendations emerging from other studies. ${ }^{8,10}$ They also have only limited resource implications.

This study employed a small highly selected sample and caution is essential in drawing any conclusions. There was little indication of problems in access to care but findings have highlighted the fact that at least some children with hearing impairments experience difficulties during care. The difficulties are not unique to dentistry but in many cases they could be easily reduced or resolved.

The authors would like to thank Susan Daniels, the chief executive of the NDCS, and Christine Pieri who helped co-ordinate the study and the regional and local representatives of the NDCS who distributed and collected the questionnaires.

1 Royal National Institute For Deaf People. Statistics on deafness. RNID Factsheet. London: RNID, 1997.

2 Tunis W, Dixter C. Dentistry and the hearing-impaired child. J Pedod 1979; 3: 321-334.

3 Rapp R, Kanar H L, Nagler B A. Pedodontic care for the deaf and blind. Dent Clin North Am 1966; 21-34.

4 Manley M C G, Leith J, Lewis C. Deafness and dental care. Br Dent J 1986; 161: 219-221.

5 O'Brien M. Children's dental health in the United Kingdom in 1993. OPCS. London: HMSO, 1994.

6 Davies A, Bamford J, Wilson I, et al. Review of the role of neo-natal hearing screening in the detection of congenital hearing impairment. Health Technol Assessment 1997; 1 (10).

7 British Deaf Association, Health Promotion Services. Survey of deaf people's health habits. London: BDA; 1995.

8 Depledge I, Meyer J. Deaf people's access to health services: an investigation into the current provisions for access to health services in the City of London and London Borough of Hackney. London: City and Hackney Joint Planning Unit, 1996.

9 Pollack J J. Communicating with the adolescent deaf patient. J Md State Dent Assoc 1976; 19: 12-14.

10 Lomas M, Thomas E. Access to health services: falling on deaf ears? Report to the Association of Greater Manchester Authorities. Carlisle: Deaf Women's Health Project, 1998. 